\title{
Impact of variability in the Indian summer monsoon on the East Asian summer monsoon
}

\author{
Richard J. Greatbatch, ${ }^{1 *}$ Xuguang Sun ${ }^{2}$ and Xiu-Qun Yang ${ }^{2}$ \\ I GEOMAR, Helmholtz-Zentrum für Ozeanforschung Kiel, Kiel, Germany \\ ${ }^{2}$ School of Atmospheric Sciences, Nanjing University, Nanjing, China
}

* Correspondence to:

R. I. Greatbatch, GEOMAR,

Helmholtz-Zentrum für

Ozeanforschung Kiel,

Düsternbrooker Weg 20, 24105

Kiel, Germany.

E-mail: rgreatbatch@geomar.de

Received: I February 2012

Revised: 6 July 2012

Accepted: 17 August 2012

\begin{abstract}
We report on model experiments that support the hypothesis that the second mode of variability of the East Asian Summer Monsoon is influenced by the variability of the Indian Summer Monsoon. The results suggest that the recent trend towards drier conditions in northern China in summer is, at least partly, a consequence of the synchronous drying trend over India in summer noted by some authors. Copyright (c) 2013 Royal Meteorological Society
\end{abstract}

Keywords: Indian summer monsoon; East Asian summer monsoon; interannual variability; trend

\section{Introduction}

In this paper, we investigate the possibility that the variability of the East Asian summer monsoon (EASM) is influenced by the variability in the Indian summer monsoon (ISM). A number of authors have commented on a link between enhanced/reduced rainfall over the Indian subcontinent and enhanced/reduced rainfall in northern China during summer (Wang et al., 2001; Ding and Wang, 2005). This link can be seen in Figure 1 which shows the correlation of summer (June/July/August) precipitation with the all Indian rainfall index (AIRI; Parthasarathy et al., 1995) over the period 1958-2001 (the precipitation data are the monthly gridded precipitation data product from Mitchell and Jones (2005). Variations in the AIRI are also associated with a circumpolar wave train (Figure 2(a)) that straddles the westerly subtropical jet stream and is similar to the circumpolar wave train discussed by Branstator (2002) for the winter season. This wave train has been discussed in detail by Ding and Wang (2005), and includes centres of action to the northwest of India and over northeastern China (Figure 2(a)). As noted by Ding and Wang (2005), the variability associated with the wave train shows synchronous rainfall anomalies of like sign over much of the Indian subcontinent and over northeast China (see their Figure 4) similar to what is shown in Figure 1. The wave train has also been noted by Xu et al. (2005) and Yang et al. (2005) who discuss the relationship between precipitation anomalies over northern China and the corresponding atmospheric and oceanic anomalies. Rainfall anomalies in summer in northeast China are also associated with the second (MVEOF2) of the two major modes of variability of the EASM, as revealed using a multi-variate empirical orthogonal function (EOF) analysis (Wang et al. (2008a); see Figure 3 in Sun et al. (2010). Sun et al. (2010) noticed a connection between the principal component time series (PC2) of MVEOF2 and the time series of the AIRI (correlation 0.59, significantly different from zero at the 99\% level) and a circumpolar wave train very similar to that shown in Figure 2(a) (see Figure 2(b)), but they were not able to establish a physical basis for these links. Anomalies in $850 \mathrm{hPa}$ height associated with an enhanced AIRI also show anomalous southerly flow across China (Figure 2c), very similar to that associated with MVEOF2 (Figure 2d), and converging in the region of enhanced rainfall over northern China. Lin (2009) has used a dry dynamical model to examine the global teleconnection pattern associated with the variability of the Asian summer monsoon, and found that a circumpolar wave train, as shown in Figure 2, is excited by a diabatic heating anomaly centred over western India.

Here we present results from experiments similar to that of Lin (2009), first using a full Atmospheric General Circulation Model (AGCM) [this is the Community Climate Model (CCM3) from National Center for Atmospheric Research (NCAR)] and then using the linear baroclinic model of Watanabe and Kimoto (2000; 2001). Our aim is to argue that the variability of the ISM drives variability of the EASM that is very similar to that associated with MVEOF2 in Sun et al. (2010), and can therefore be viewed as the underlying driving mechanism for MVEOF2. We then connect the recently reported declining trend in Indian summer rainfall (Bollasina et al., 2011) to the trend towards 'south flood/north drought' in China in recent decades (Zhu and Yang, 2003; Yang et al., 2004; Zhu et al., 2007; Wang et al., 2008b) and argue that the 


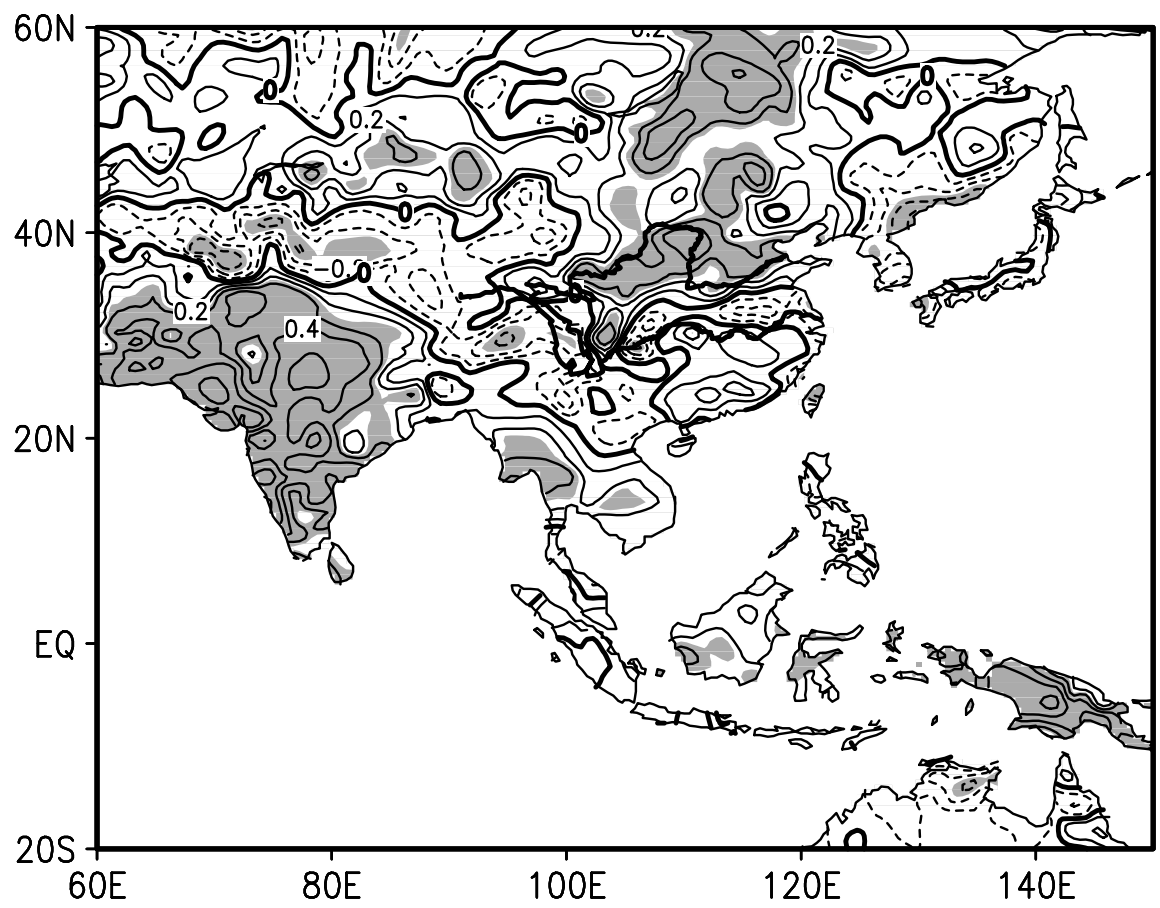

Figure I. Correlation of summer (JJA) rainfall against the AIRI. Rainfall data are taken from monthly, gridded precipitation data CSU TS 2.I of the Climatic Research Unit at the University of East Anglia (Mitchell and Jones, 2005). All data are for the period 1958-200I. Shading indicates regions where the associated correlation is significantly different from zero at the $95 \%$ level. Positive values and the zero contour are shown by solid contours, negative values by dashed contours.

drying trend over northern China may be a consequence of the reported drying trend over India.

The plan of the paper is as follows. In Section 2 we discuss the model results from the CCM3 AGCM and in Section 3 from the linear model. Section 4 provides a summary and discussion.

\section{The CCM3 model}

The version of the Community Climate Model used here is the fourth generation global spectral model of the NCAR. It is triangular truncated with a horizontal T42 spectral resolution (approximately $2.8^{\circ} \times 2.8^{\circ}$ in latitude/longitude space). The model has 18 levels in the vertical direction with the model top at $2.9 \mathrm{hPa}$. The model time step is $20 \mathrm{~min}$. The model includes a diurnal cycle, interactive moisture and a detailed physical model for land surface processes. Detailed descriptions of all the physical processes and numerical methods used in CCM3 are provided by Kiehl et al. (1998). The model is forced by adding an idealized diabatic heating anomaly over India, as shown in Figure 3. The pattern of heating is chosen to mimic the anomalous diabatic heating associated with anomalies of the AIRI and the chosen amplitude (maximum close to $3 \mathrm{~K} \mathrm{day}^{-1}$ ) is similar to that implied by Figure 5 of Sun et al. (2010). The location for the imposed anomalous heating is a little to the east of that used by Lin (2009). Tests using the linear model described in the next section show that this difference has very little effect. Climatological sea surface temperature (SST) is prescribed at the lower boundary and the model is run from May 21 to August 31. There are ten ensemble members all with different initial conditions taken from an unperturbed control run (the control run has no extra diabatic heating anomaly and uses climatological SST). Model output is averaged over June, July and August, and over all ten ensemble members, for analysis.

Figure 4(a) and (c) shows the model response to the applied heating over India at both 200 and $850 \mathrm{hPa}$. The shading indicates that the model ensemble mean (the plotted field) is significantly different from zero at the $95 \%$ level. At $200 \mathrm{hPa}$ (Figure 4(a)), we see a circumpolar wave train very similar in both shape and amplitude to that shown in Figure 2(a) with positive height anomalies to the west of northern India and over northern China. The latter, and also the positive anomaly further east, meets the $95 \%$ significance threshold indicated by the shading. There is also a negative anomaly to the north and west of India that fails to make the $95 \%$ threshold but nevertheless appears as two separate, weaker anomalies in the regression analysis (Figure 2(a) and (b)). These results support the view that the diabatic heating of the atmosphere due to latent heat release associated with the ISM plays a role in exciting the circumpolar wave train of Ding and Wang (2005) (consistent with the results of Lin (2009) and also the pattern at $200 \mathrm{hPa}$ that goes along with MVEOF2 from Sun et al. (2010) (Figure 2(b)). The mechanism for exciting the wave train, and an associated teleconnection from the ISM to the Euro-Atlantic sector, is discussed in Lin and 
(a) $200 \mathrm{hPa}$ HGT regressed on AIRI

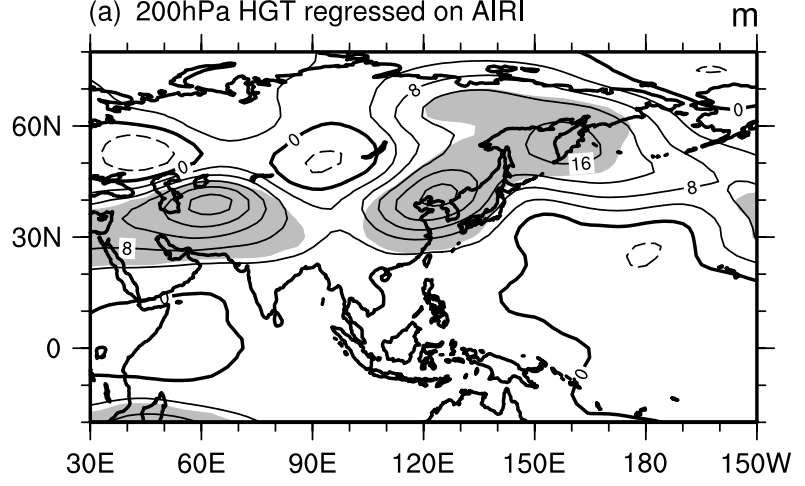

(c) $850 \mathrm{hPa}$ wind regressed on AIRI

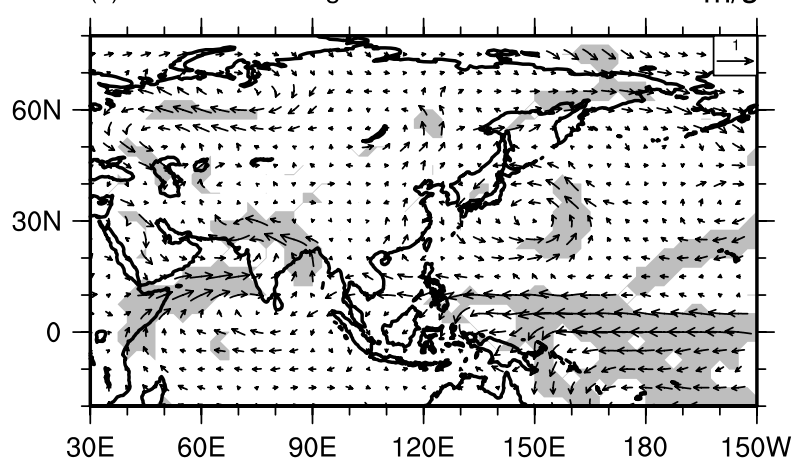

(b) $200 \mathrm{hPa}$ HGT regressed on PC2

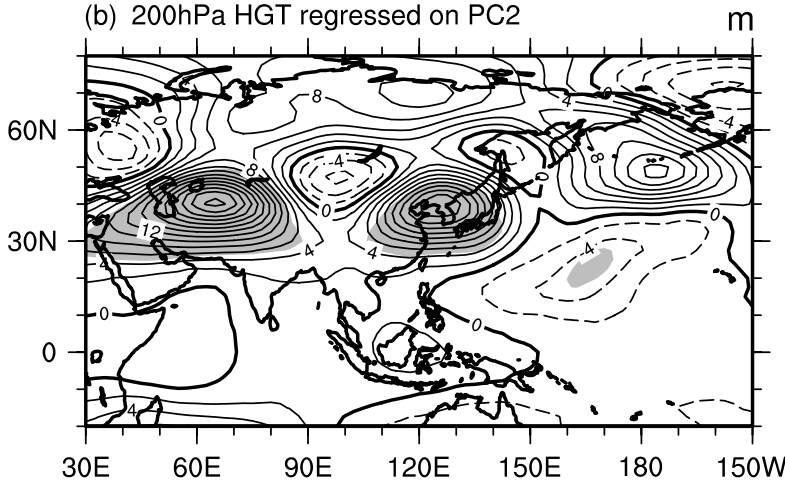

(d) $850 \mathrm{hPa}$ wind regressed on PC2

$\mathrm{m} / \mathrm{s}$

Figure 2. Patterns obtained by regression of interannual JJA anomalies of (I) $200 \mathrm{hPa}$ height (contour interval $4 \mathrm{~m}$ ) against (a) the AIRI and (b) PC2 and (2) $850 \mathrm{hPa}$ wind against (c) the AIRI and (d) PC2. Shading indicates regions where the associated correlation coefficients are significantly different from zero at the $95 \%$ level.

Diabatic Heating Forcing in LBM
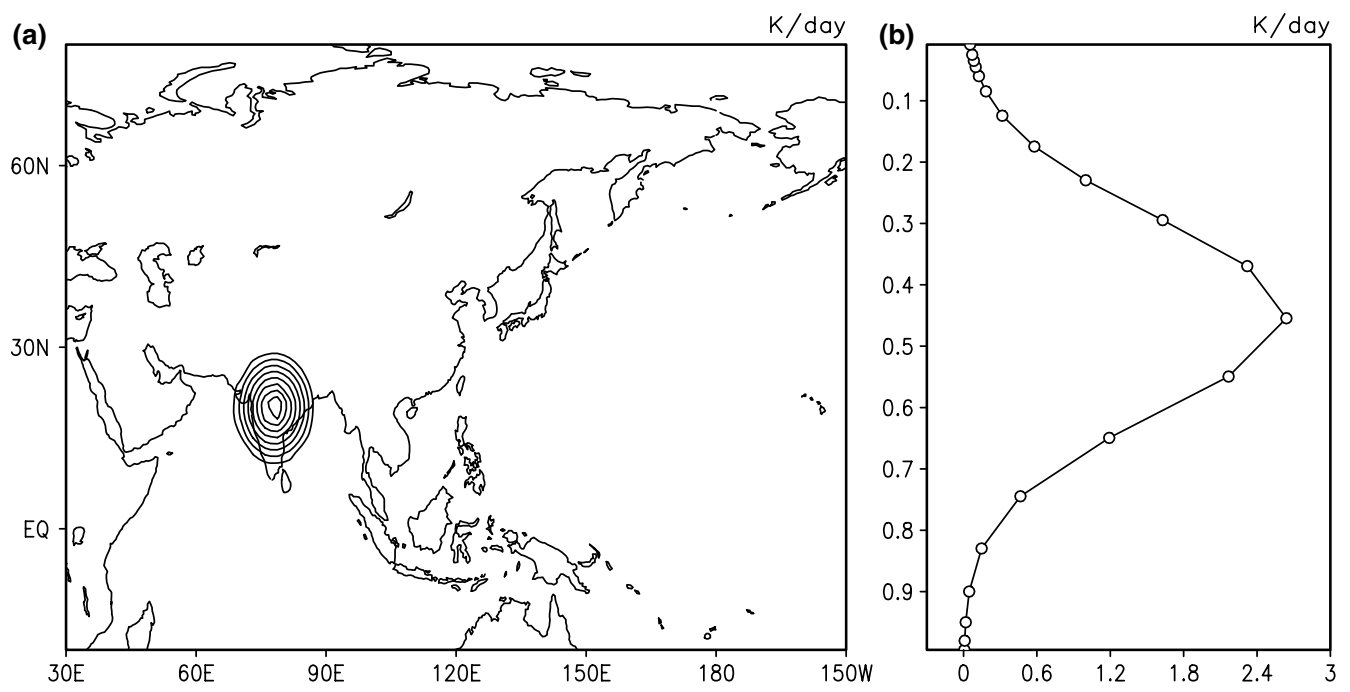

Figure 3. The (a) horizontal and (b) vertical structures of the heating anomaly used to drive both models.

$\mathrm{Wu}$ (2012). At $850 \mathrm{hPa}$, the significance level of the model response is somewhat lower, although the general pattern is again consistent with MVEOF2 (cf. Figure 2(d)) and the anomalous northward flow over China almost meets the 95\% threshold. The model precipitation response (Figure 5) shows, not surprisingly, enhanced precipitation over India and a rather weak response to the east. Nevertheless, there is the suggestion of a region of enhanced rainfall over central and northwestern China not unlike that in Figure 1 (the feature over central China just about makes the $90 \%$ significance threshold), although the bands of anomalous precipitation in the model tend to be displaced southward, perhaps reflecting the coarseness of the model resolution.

\section{The linear model}

The linear model is the same as that used by Watanabe and Kimoto $(2000,2001)$ except that here the model 
(a) $200 \mathrm{hPa} \mathrm{HGT}$ in CCM3

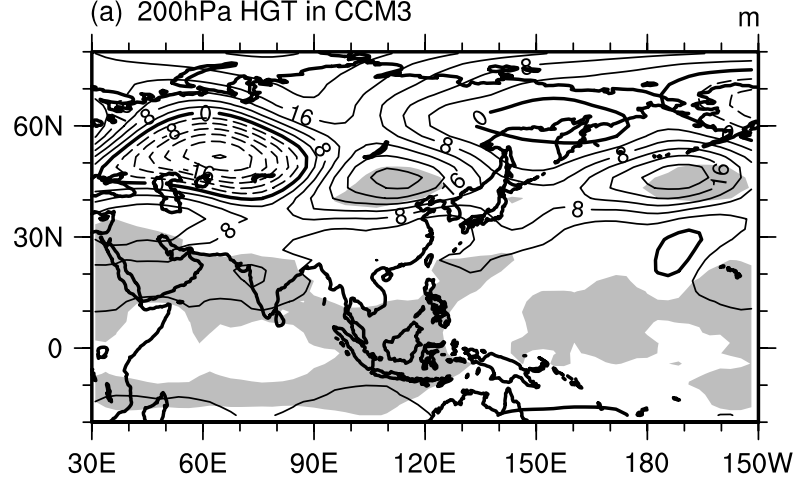

(b) $200 \mathrm{hPa} H G T$ in LBM
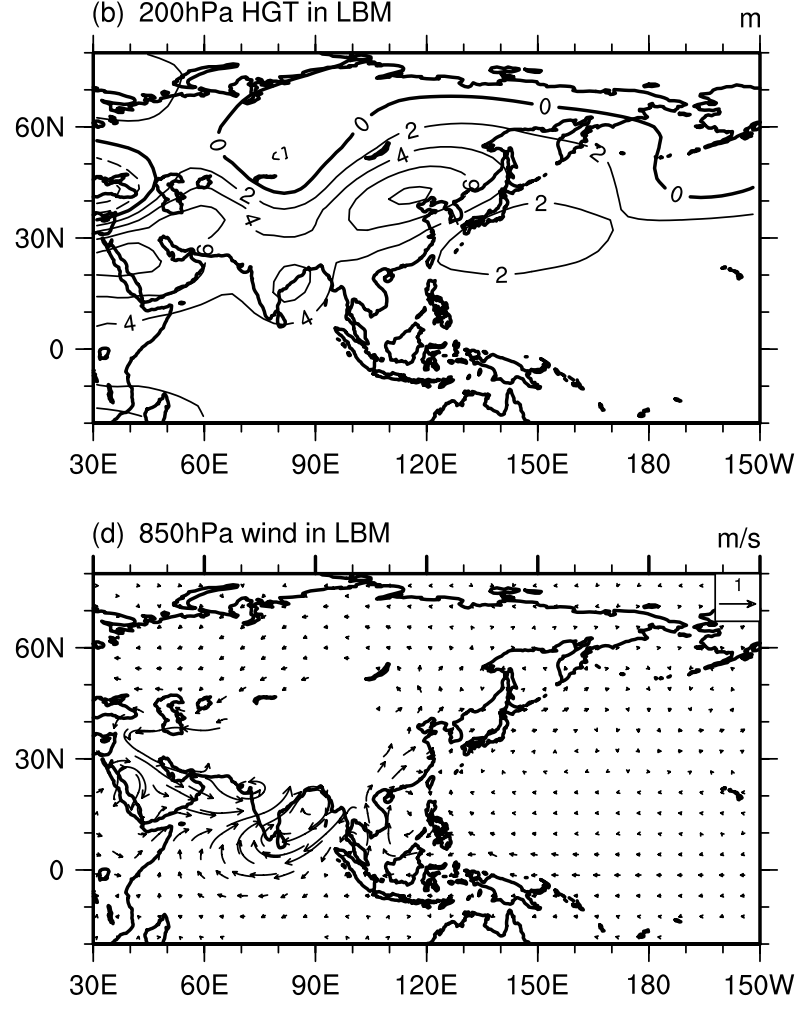

Figure 4. The (a,b) $200 \mathrm{hPa}$ height and (c,d) $850 \mathrm{hPa}$ wind anomalies generated by $(\mathrm{a}, \mathrm{c})$ the CCM3 model and (b,d) the linear baroclinic model. The contour intervals in parts (a) and (b) are 4 and $2 \mathrm{~m}$ respectively. The scales for wind arrows in (c) and (d) are shown in the top right corner. The shading in (a) and (c) indicates that the plotted (ensemble mean) field is significantly different from zero at the $95 \%$ level.

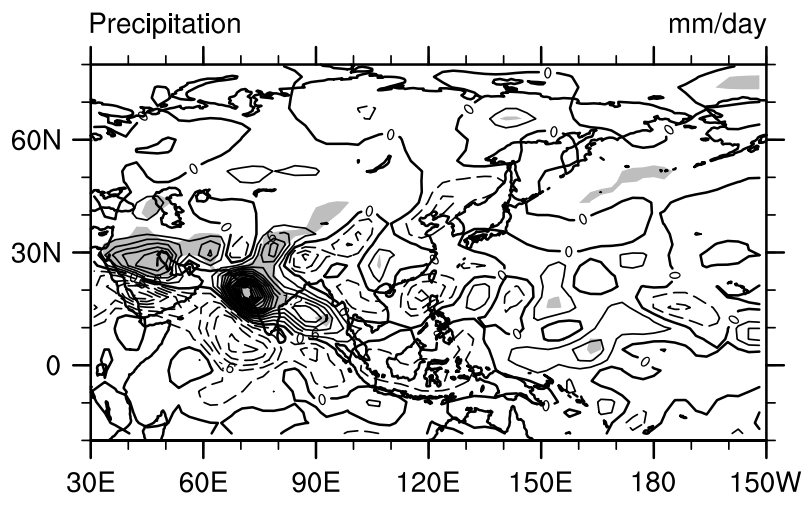

Figure 5. The model response in precipitation from the $\mathrm{CCM} 3$ model. The shading shows the $90 \%$ significance level. Solid contours indicate enhanced precipitation and dashed contours reduced precipitation. The contour interval is $0.3 \mathrm{~mm}^{\text {day }}{ }^{-1}$.

set-up is basically as in $\mathrm{Lu}$ and Lin (2009). In particular, the model integrates the dry primitive equations linearized about the mean JJA climatology obtained from the ERA-40 reanalysis and includes orography with realistic amplitude. The horizontal resolution of the model is T42 (corresponding roughly to $2.8^{\circ} \times 2.8^{\circ}$ in latitude and longitude) and in the vertical there are 20 unevenly spaced sigma (orography following) levels. Details of the model setup can be found in Sun et al. (2010). The model is forced by an idealized diabatic heating anomaly centred in the mid-troposphere over India, exactly as was used to force the CCM3 model described in the previous section (Figure 3). The model is integrated for 30 days and a steady state is reached after about 15 days of integration. Here we show the results at day 20.

Figure 4(b) shows the model solution at $200 \mathrm{hPa}$, indicating some success at reproducing the northern hemisphere circumpolar wave train (Figure 2(a) and (b)) but with reduced amplitude (note that the contour interval used in Figure 4(b) is only 2 m compared with $4 \mathrm{~m}$ in Figure 4(a). Note, in particular, the anomalous highs, first over and to the east of the Caspian Sea and, second, centred near the head of the Bohai Sea in northeast China, with an anomalous trough lying between (the trough is more pronounced in the regression analysis and also in the CCM3 model than in Figure 4(b)). Figure 4(d) shows the circulation pattern at $850 \mathrm{hPa}$ that is generated by the model. It is clear that while the amplitude of the model response over India is somewhat larger compared with other regions, the main features of the regression pattern (Figure 2(c)) are, nevertheless, reproduced. In particular, one can see anomalously northward flow over eastern China associated with a subtropical anomalous high centred in the model over the South China Sea (readers are referred to Xie et al. (2009) for further discussion on the dynamics of the anomalous high which is related to the eastward propagating Kelvin wave generated by the imposed diabatic forcing). This anomalous northward flow, whose 
amplitude compares well with that in the regression plot, compares better with the pattern shown in Figure 2(d) than the model solution previously found by Sun et al. (2010) (see their Figure 6d). Here the flow extends fully into northern China rather than exiting China across Korea and Japan. Furthermore, there are anomalous easterly winds along the equator, as found in the regression patterns, and which Sun et al. (2010) argue are important for generating the La Nina in the tropical Pacific that tends to follow summers with positive values of PC2 (or, indeed, positive values of the AIRI). Easterly wind anomalies along the equator can also be seen in the CCM3 case (Figure 4(c)), especially near the Maritime Continent region. Near the forcing region itself there is anomalous southwesterly flow into the Indian subcontinent, with an anticyclonic flow anomaly over the Bay of Bengal, not unlike that seen in the regression plots.

The model has also been forced using a diabatic heating anomaly specified over northern China. In this case, the model response (not shown) is highly localized and there is no signal over India. The result supports our view that the causality is from the variability of the ISM to that of the EASM and not the other way round.

\section{Summary and discussion}

Sun et al. (2010) identified two major modes of variability of the EASM using a multi-variate EOF (MVEOF) analysis, following Wang et al. (2008a). They noticed a connection between the second mode (MVEOF2), which in the positive phase is associated with enhanced rainfall over northern China, and the AIRI, but were unable to give a physical basis for the connection. Here we have used both a fully nonlinear AGCM with moisture (CCM3) and a dry dynamical model forced by idealized diabatic heating anomalies to argue that the second mode is a dynamical response to diabatic heating anomalies over India associated with the variability of the ISM (be there also a masking effect from atmospheric noise, as indicated by the failure of the CCM3 model response to always pass the $95 \%$ significance threshold). Sun et al. (2010) noted that the first mode of variability identified by the EOF analysis corresponds to the Pacific-Japan pattern (Nitta, 1987). Interestingly, there is no significant correlation between the time series of the first mode of variability and the AIRI, indicating that the two phenomena are, indeed, distinct.

While we have been able to connect the variability of the ISM to that of the EASM, we are not able here to address the much more complex issue of what controls the variability in the ISM or the AIRI, in particular. Understanding the variability of the ISM is beyond the scope of this paper but remains one of the outstanding issues in tropical meteorology. Bollasina et al. (2011) present evidence for an ongoing decline in ISM rainfall that coincides with the emergence of the 'south flood/north drought' pattern of precipitation over China during summer in recent decades, e.g. Zhu and Yang (2003), Yang et al. (2004), Zhu et al. (2007) and Wang et al. (2008b). Sun et al. (2010) have also noted a downward trend in the principal component time series of MVEOF2 that is consistent with the trend towards drier conditions in summer in the north and wetter conditions further south in China. The results we have presented here argue for a link between the two phenomena, a decline in ISM rainfall and the emergence of a 'south flood/north drought' pattern of rainfall over China, with the causality being from the former to the latter.

Finally, we have focused on the impact of anomalies in the diabatic heat release associated with the ISM on the neighbouring EASM. There is also the possibility that anomalies over the Tibetian plateau might also influence the EASM, as has been suggested, for example, by Wang et al. (2008b) and Wu et al. (2012). While beyond the scope of the present study, the possible role of heating anomalies over the Tibetian plateau remains a topic for future study.

\section{Acknowledgements}

$\mathrm{XS}$ is grateful for support from the National Key Basic Research Program (973) under Grant No. 2012CB417203 and 2010CB428504, the National Natural Science Foundation of China (40705028, 40730953), the National Public Benefit Research Foundation of China under Grant No. GYHY200806004, and the Jiangsu Natural Science Foundation under Grant No. BK2008027. RJG acknowledges support from GEOMAR and thanks his co-authors for their hospitality during a recent visit to Nanjing University. The authors thank Yiquan Jiang of Nanjing University and Drs Mike Blackburn and Andrew Turner of Reading University, UK, for helpful discussions. They are also grateful to two anonymous reviewers for their helpful comments.

\section{References}

Bollasina MA, Ming Y, Ramaswamy V. 2011. Anthopogenic aerosols and the weakening of the South Asian Summer Monsoon. Science 28: 502-333, DOI: 10.1126/science.1204994.

Branstator G. 2002. Circumpolar teleconnections, the jet stream waveguide, and the North Atlantic Oscillation. Journal of Climate 15: $1893-1910$.

Ding Q, Wang B. 2005. Circumpolar teleconnection in the Northern Hemisphere summer. Journal of Climate 5: 541-560.

Kiehl JT, Hack JJ, Bonan GB, Boville BA, Williamson DL, Rasch PJ. 1998. The National Center for Atmospheric Research Community Climate Model: CCM3. Journal of Climate 11: 1131-1149.

Lin H. 2009. Global extratropical response to diabatic heating variability of the Asian summer monsoon. Journal of the Atmospheric Sciences 66: 2697-2713.

Lin $\mathrm{H}, \mathrm{Wu}$ Z. 2012. Indian summer monsoon influence on the climate in the North Atlantic-European sector. Climate Dynamics 39: 303-311, DOI: 10.1007/s00382-011-1286-8.

Lu R, Lin Z. 2009. Role of subtropical precipitation anomalies in maintaining the summertime meridional teleconnection over the western North Pacific and east Asia. Journal of Climate 22: 2058-2072.

Mitchell TD, Jones PD. 2005. An improved method of constructing a database of monthly climate observations and associated 
high-resolution grids. International Journal of Climatology $\mathbf{2 5}$ : $693-712$.

Nitta T. 1987. Convective activities in the tropical western Pacific and their impact on the northern hemisphere summer circulation. Journal of the Meteorological Society of Japan 65: 373-390.

Parthasarathy B, Muno AA, Kothawale DR. 1995. Monthly and seasonal rainfall series for All-India homogeneous regions and meteorological subdivisions: 1871-1994. Contributions from Indian Institute of Tropical Meteorology, Research Report RR-065, 1995, Pune, India.

Sun X, Greatbatch RJ, Park W, Latif M. 2010. Two major modes of variability of the East Asian Summer Monsoon. Quarterly Journal of the Royal Meteorological Society 136: 829-841, DOI: 10.1002/qj.635.

Wang B, Wu R, Lau K-M. 2001. Interannual variability of the Asian Summer Monsoon: contrasts between the Indian and Western North Pacific-East Asian Monsoons. Journal of Climate 14: 4073-4090.

Wang B, Wu Z, Li J, Liu J, Chang C-P, Ding Y, Wu G. 2008a. How to measure the strength of the East Asia Summer Monsoon. Journal of Climate 21: 4449-4463.

Wang B, Bao Q, Hoskins BJ, Wu G, Liu Y. 2008b. Tibetian Plateau warming and precipitation changes in East Asia. Geophysical Research Letters 35: L14702, DOI: 10.1029/2008GL034330.

Watanabe M, Kimoto M. 2000. Atmosphere-ocean thermal coupling in the North Atlantic: a positive feedback. Quarterly Journal of the Royal Meteorological Society 126: 3343-3369.
Watanabe M, Kimoto M. 2001. Corrigendum. Quarterly Journal of the Royal Meteorological Society 127: 733-734.

Wu Z, Li J, Jiang Z, Ma T. 2012. Modulation of the Tibetian Plateau snow cover on the ENSO teleconnections: From the East Asian Summer Monsoon perspective. Journal of Climate 25: $2481-2489$.

Xie S-P, Hu K, Hafner J, Tokinaga H, Du Y, Huang G, Sampe T. 2009. Indian Ocean capacitor effect on Indo-Western Pacific climate during the summer following El Nino. Journal of Climate 22: 730-747.

Xu GY, Yang X-Q, Sun X. 2005. Interdecadal and interannual variation characteristics of rainfall in North China and its relation with northern hemisphere atmospheric circulations (in Chinese). Chinese Journal of Geophysics 48(3): 511-518.

Yang X-Q, Zhu YM, Xie Q, Ren XJ, Xu GY. 2004. Advances in studies of Pacific Decadal Oscillation (in Chinese). Chinese Journal of Atmospheric Sciences 28: 979-992.

Yang X-Q, Xie Q, Zhu YM, Sun X, Guo YJ. 2005. Decadal to interdecadal variability of precipitation in North China and associated atmospheric and oceanic anomaly patterns (in Chinese). Chinese Journal of Geophysics 48(4): 789-797.

Zhu YM, Yang X-Q. 2003. Relationships between Pacific Decadal Oscillation (PDO) and climate variabilities in China (in Chinese). Acta Meteorologica Sinica 61: 641-654.

Zhu X, He J, Wu Z. 2007. Meridional seasaw-like distribution of the Meiyu rainfall over the Changjiang-Huaihe river valley and characteristics in the anomalous climate years. Chinese Science Bulletin 52(17): 2420-2428. 